
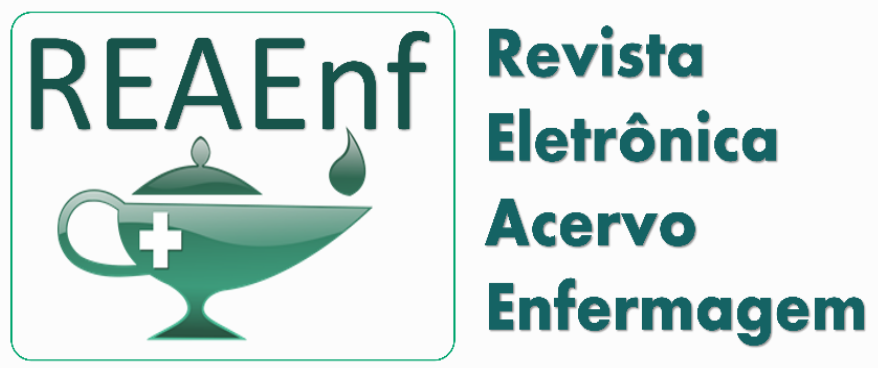

REVISÃO BIBLIOGRÁFICA

Recebido em: 9/2020

Aceito em: $10 / 2020$

Publicado em: 11/2020

\title{
Mito ou verdade? Educação em saúde com gestantes sobre aleitamento materno exclusivo
}

\author{
Myth or truth? Health education with pregnant women about exclusive breastfeeding \\ ¿Mito o verdad? Educación para la salud con mujeres embarazadas sobre lactancia \\ materna exclusiva
}

Elem Cristina Silva da Costa $^{1}$, Elma de Sousa Fontoura ${ }^{1}$, Sandiely Lorrainy de Carvalho Souza ${ }^{1}$, Adriana Paiva Camargo Saraiva ${ }^{1 *}$

\begin{abstract}
Resumo: Esse artigo buscou relatar a experiência de acadêmicas do curso de enfermagem de uma universidade do interior do Pará na realização de atividade de educação em saúde com gestantes de um projeto social sobre Aleitamento Materno Exclusivo (AME). Informações de artigos científicos e de uma cartilha do Ministério da Saúde Brasileiro nortearam o material didático utilizado para destacar mitos e verdades relacionados ao AME. A atividade educativa foi realizada por meio do compartilhamento de conhecimentos e de experiências no formato de "roda de conversa" com incentivo à interação entre as participantes do projeto social envolvido. A atividade contribuiu para a percepção da necessidade de promover mais ações de educação em saúde. Foi possível apontar mitos e crenças influenciam negativamente o sucesso do Aleitamento Materno Exclusivo e que é necessário que a cultura do conhecimento baseado em evidências se sobressaia em relação aos mitos que ainda permeiam o cotidiano da população envolvida. Tal conhecimento deve ser exposto de maneira simples, didática e com linguagem adequada ao público alvo para facilitar o entendimento.
\end{abstract}

Palavras-chave: Educação em saúde, Aleitamento materno, Gestantes.

\begin{abstract}
This article aims to report the experience of nursing students at a university in the interior of Pará was performed health education activities with pregnant women in a social project on Exclusive Breastfeeding (EBF). Information from scientific articles and a guideline from the Brazilian Ministry of Health guided the teaching material used to highlight myths and truths related to EBF. The educational activity was performed through the sharing of knowledge and experiences in the "conversation circle" format, encouraging interaction between the participants of the social project involved. The activity contributed to the perception of the need to promote more health education actions. It was possible to demonstrate myths and that negatively influence the success of Exclusive Breastfeeding and that it is necessary that the culture of knowledge based on evidence stands out in relation to the myths that still permeate the daily lives of the population involved. Such knowledge must be exposed in a simple, didactic manner and with language appropriate to the target audience to facilitate understanding.
\end{abstract}

Keywords: Health education, Breast feeding, Pregnant women.

${ }^{1}$ Universidade do Estado do Pará (UEPA), Conceição do Araguaia - PA. *E-mail: adriana.saraiva@uepa.br 
Resumen: Este artículo buscó relatar la experiencia de estudiantes de enfermería de una universidad del interior de Pará en la realización de actividades de educación en salud con mujeres embarazadas en un proyecto social sobre lactancia materna exclusiva (LME). La información de artículos científicos y un guía del Ministerio de Salud de Brasil guió el material didáctico utilizado para resaltar los mitos y verdades relacionados con la LME. La actividad educativa se llevó a cabo mediante el intercambio de conocimientos y experiencias en el formato de "círculo de conversación", fomentando la interacción entre las participantes del proyecto social involucrado. La actividad contribuyó a la percepción de la necesidad de impulsar más acciones de educación en salud. Se pudo señalar mitos y creencias que influyen negativamente en el éxito de la Lactancia Materna Exclusiva y que es necesario que la cultura del conocimiento basada en la evidencia se destaque en relación a los mitos que aún permean la vida cotidiana de la población involucrada. Dicho conocimiento debe exponerse de forma sencilla, didáctica y con un lenguaje adecuada al público objetivo para facilitar la comprensión.

Palabras clave: Educación en salud, Lactancia materna, Mujeres embarazadas.

\section{INTRODUÇÃO}

O Aleitamento Materno Exclusivo (AME) é caracterizado pela oferta apenas do leite materno diretamente dos seios ou ordenhado, sob livre demanda ao recém-nascido, sem a presença de outros líquidos ou sólidos. A Organização Mundial da Saúde (OMS) preconiza que o AME se inicie ainda na sala de parto na primeira hora de vida e posteriormente ser ofertado até o sexto mês de vida do neonato. A partir de então, é recomendado introduzir a alimentação complementar, oferecendo outros líquidos e alimentos até os dois ou três anos de idade, onde geralmente ocorre o desmame naturalmente (CAMPOS MAS, et al., 2015; BRASIL, 2016).

Um dos maiores desafios relacionados ao AME é o desmame precoce. Embora existam diversas pesquisas científicas que evidenciam que o AME proporciona inúmeros benefícios tanto para a mãe quanto para a criança, o desmame precoce ainda é considerado um problema de saúde pública em todo o mundo (BRASIL, 2014).

Tal problema pode ser fortemente influenciado por atitudes adquiridas socialmente. Isso por ocasião de as mães tornarem-se muito susceptíveis a crenças, mitos e tabus que podem transformar-se em práticas prejudiciais à amamentação (ALGARVES TR, et al., 2015).

O mito é caracterizado pela representação de personagens ou acontecimentos reais colocados de forma exagerada por grande parte da população, chegando a se tornar tradição em comunidades ou famílias. Já a tradição é a propagação oral de lendas, conhecimentos ou práticas de geração em geração. Desse modo, o mito possui relação direta com a própria tradição, podendo possuir teor que contradiz a verdade. Estando presente na sociedade, quando efetivo, estimula pensamentos e comportamentos prejudiciais ao indivíduo como, por exemplo, na prática da amamentação (ALGARVES TR, et al., 2015).

Dentre os mitos associados à cultura materna, que entram em conflito com as recomendações dos órgãos de saúde e que levam ao desmame precoce, destacam-se o mito do leite insuficiente, do leite fraco, da queda dos seios com a lactação, a crença de que o leite secou e que o bebê não consegue sugar e/ou não conseguiu pegar o peito e, devido a isso, necessita de outros líquidos (FARIA MC, 2014; OLIVEIRA AKP, et al., 2017).

Várias pesquisas científicas salientam os benefícios do Aleitamento Materno e consideram o leite materno como o único alimento ofertado que garante melhor qualidade de vida para a criança, já que fornece as proporções ideais de proteínas, açúcares, gorduras, água e vitaminas indispensáveis para o crescimento e o desenvolvimento saudável do recém-nascido até a vida adulta (MARQUES ES, et al., 2011; LODI JC, 2016; ALBUQUERQUE RCCS, et al., 2019).

Informações equivocadas ou sem embasamento científico, juntamente com a falta de orientação, contribuem para uma amamentação insatisfatória que pode levar ao desmame precoce. Logo, é 
indispensável identificar os conhecimentos, crenças e atitudes que a mulher detém, bem como suas experiências em relação ao aleitamento. Com informações e assistência de qualidade, a mulher pode sentirse confiante e acreditar em sua capacidade para amamentar e exercê-la com sucesso (SEPKA GC, et al., 2007).

A educação em saúde permite trabalhar a realidade e propor ações transformadoras por meio do pensamento crítico reflexivo, capaz de levar o indivíduo a ter sua autonomia e independência como um ser histórico e social (FALKENBERG MB, et al., 2014).

Portanto, o AME ocupa lugar de destaque entre as ações básicas de saúde recomendadas pela Organização Mundial de Saúde (OMS), e o profissional da saúde tem uma grande responsabilidade nesta prática, uma vez que contribui para seu êxito por meio do incentivo às gestantes com atitudes ativas que as ajudem em suas dificuldades (BRASIL, 2016).

Assim, Independente do nível de formação, a enfermagem ocupa um importante papel nesta promoção do saber e criação de um ambiente favorável para que a educação em saúde ocorra. Sempre que possível, deve-se adotar uma filosofia de caráter participativo, com abordagem educativa dinâmica, envolvendo os aprendizes de forma ativa (BASTABLE SB, 2010).

Diante do exposto, o presente trabalho objetivou relatar a experiência de acadêmicas do curso de enfermagem em uma universidade do estado do Pará, na realização de uma ação de educação em saúde com gestantes de um projeto social em um município do interior do Pará, acerca do Aleitamento Materno Exclusivo, destacando os mitos e verdades relacionados a essa prática.

O trabalho descreve como transcorreu a ação educativa, feita de forma dinâmica, com a desmitificação de temas associados ao AME através do compartilhamento de conhecimentos.

\section{RELATO DE EXPERIÊNCIA}

Este trabalho relata a vivência de discentes do curso de graduação em enfermagem na realização de uma ação de educação em saúde sobre os mitos e verdades relacionadas à prática do Aleitamento Materno Exclusivo, com gestantes do projeto social "Sonho de Mãe" realizada em setembro de 2019.

O "Projeto Sonho de Mãe" é uma iniciativa da igreja católica, presente em vários municípios do Brasil e do mundo, que acolhe gestantes em risco social, oferece apoio por meio de palestras e oficinas de saúde da gestante e do bebê; e de artesanato e corte e costura, com o intuito de que as próprias gestantes produzam o seu enxoval e cuidem de si e dos seus bebês.

A ação contou com 10 (dez) participantes, incluindo primíparas e multíparas, e foi realizada no período vespertino com a presença das coordenadoras, discentes de enfermagem e gestantes. A abordagem se deu por meio de roda de conversa, com o uso da dinâmica de mitos e verdades. Utilizou-se uma caixa com afirmativas e placas com as opções "mito" e "verdade", para que as afirmativas fossem julgadas pelas participantes.

A dinâmica foi norteada pelo Caderno de Atenção Básica "Saúde da Criança: Aleitamento Materno e Alimentação Complementar" do Ministério da Saúde (2015); e artigos científicos que tratassem a respeito da temática. A partir disso, as afirmativas foram elaboradas.

Inicialmente, apresentou-se o tema que seria abordado e como seria desenvolvido. Em seguida distribuiu-se uma placa com as alternativas para cada participante e, posteriormente, a caixa com as afirmativas percorreu a roda, onde cada integrante retirava uma afirmativa, a mesma era exposta ao grupo e todas julgavam com a placa.

A caixa contou com as afirmativas: "É recomendável dar leite de vaca para o bebê" ; "Existe mulher que não produz leite suficiente para o bebê"; Existe leite fraco"; "O aleitamento prejudica o seio da mulher"; "O aleitamento Materno deve ser exclusivo nos primeiros seis meses de vida do bebê"; "A amamentação ajuda a mulher a retornar ao peso de antes da gravidez"; "A amamentação ajuda a prevenir o câncer de mama";

REAEnf/EJNC | Vol. 6 | e5375 | DOI: https://doi.org/10.25248/REAenf.e5375.2020 Página 3 de 6 
"A amamentação é considerada um método anticoncepcional nos primeiros 6 meses após o parto"; "Bebê que mama no peito não pode beber água"; "A pega incorreta pode desencadear fissura nos mamilos".

As gestantes tiveram participação ativa na dinâmica, fizeram seus questionamentos e partilharam suas experiências com a prática da amamentação. Ao final de cada afirmação, abria-se o espaço para abordar o tema.

\section{DISCUSSÃO}

Ocorre de muitas das vezes, a lactante possuir conhecimentos sobre assuntos relacionados ao AM, porém, estes conhecimentos não se refletem em sua prática. Desta forma, apesar de os conhecimentos sobre os benefícios do AM para a mãe e a criança existirem, os índices de AM ainda se encontram baixos em vista de diversos fatores que influenciam esta prática, de modo inclusivo o contexto sociocultural e familiar na qual a mulher está inserida (SANTOS EM, et al., 2019).

A primeira afirmação discutida foi: "É recomendável dar leite de vaca para o bebê". A maioria das participantes julgou ser verdade, o que não corrobora com a literatura, pois a ingesta de leite de vaca pode causar alergia no bebê e não nutrí-lo adequadamente. Logo, o que pode aumentar a produção láctea, é a sucção frequente do bebê (BRASIL, 2018).

A segunda afirmativa se referiu a hipogalactia: "Existe mulher que não produz leite suficiente para o bebê". As participantes julgaram a afirmativa como verdadeira. Sim, é verdade, mas é um fenômeno muito raro e muitas mães acreditam que não produzem leite suficiente. Quanto a isso, a produção de leite pela grande maioria das mulheres é suficiente para suprir as necessidades nutricionais da criança, porém, se o número de mamadas for reduzido, ocorre prejuízo na liberação hormonal da prolactina e ocitocina, consequentemente interferindo na produção e ejeção láctea, ou seja, o estímulo da produção, que é feito através da sucção do bebê, também diminui, e desse modo, a produção do leite materno é reduzida (ARAGAKI IMM, 2002).

A terceira afirmativa foi: "Existe leite fraco". Essa foi a afirmativa que quase todas erraram e que levantou uma discussão sobre a incompreensão do choro da criança e de influência de crenças de parentes e amigos. Uma das gestantes relatou que em sua primeira experiência com a amamentação não ofereceu AME ao seu filho, pois os familiares diziam que a criança chorava porque sentia fome. $O$ fato de não compreender o motivo do choro da criança a levou a iniciar alimentação complementar precocemente no lactente. O mito do leite fraco é reforçado na comparação do leite de vaca com o leite humano. Este último, que aparenta ser "aguado", faz com que a mãe o considere fraco e introduza alimentação complementar. A aparência aguada é normal (BRASIL, 2017).

A quarta afirmativa foi: "O aleitamento materno prejudica os seios da mulher". As participantes expressaram dúvidas em relação a esta afirmativa, mas a maioria considerou a alternativa verdadeira. A queda dos seios com a lactação é outro mito. A maioria das mulheres acredita que quanto maior o período de amamentação, maiores serão as consequências estéticas nos seios, que irão se tornar flácidos e caídos. Fato equivocado, pois a queda dos seios não está associada à amamentação, e sim à sustentação incorreta, o que pode ser evitado com sutiãs adequados (COSTA FR, 2019).

A quinta afirmativa: "A pega incorreta pode desencadear fissura nos mamilos". As gestantes multíparas relataram suas experiências e afirmaram ser "verdade". No que diz respeito ao bebê não conseguir fazer a pega correta do peito, é fato que nos seus primeiros dias de vida, podem apresentar dificuldade para sugar, mas a falta de orientação de enfermagem para as mães durante a gestação culmina em reforçar o mito de "o bebê não querer pegar o peito" e assim, ocorrer grande parte do desmame precoce (MARQUES ES, et al., 2011).

As afirmativas de sexta e a sétima ordem: "Bebê que mama no peito não precisa de água" e "O aleitamento materno deve ser exclusivo nos primeiros 6 meses de vida do bebê", nem todas responderam corretamente, pois consideraram a alternativa como "mito". Foi orientado que a introdução precoce de líquidos ao neonato como, por exemplo, água e chás, muitas vezes acontece em virtude de a mãe acreditar 
que o leite não sacia a sede do bebê e que o chá acalma e alivia as cólicas. A ingestão desses líquidos pode confundir a saciedade do lactente e, como consequência, diminuir a quantidade de mamadas. $E$, além disso, aumentar o risco do desenvolvimento de infecções, como a diarréia. O Ministério da Saúde estima que o AME previna cerca de $13 \%$ da mortalidade por doenças evitáveis em menores de 5 anos de idade (MARQUES ES, et al., 2011; BRASIL, 2014).

A oitava, nona e décima afirmativas: "A amamentação ajuda a prevenir o câncer de mama"; "Amamentar ajuda a mulher retorna ao peso de antes da gravidez" e "A amamentação é considerada um método anticoncepcional nos primeiros seis meses após o parto". Em relação a essas três últimas afirmativas as gestantes julgaram as afirmativas como "mito". Diante das informações e experiências das gestantes, percebeu-se divergências com as afirmativas, encontrando-se uma certa dificuldade para convencê-las de que as afirmativas são "verdadeiras". A amamentação exclusiva promove a involução uterina, intensifica a perda de peso materna, reduz o sangramento vaginal, melhora a remineralização óssea da mãe e diminui o risco de cânceres de ovário e de mama, além de ter efeito contraceptivo (BOER NCP, 2017; BRASIL, 2018).

Um ponto importante que foi discutido na roda de conversa foi o uso de mamadeiras e chupetas, práticas que interferem no AME e podem ser responsáveis pelo desmame precoce. $O$ bebê pode preferir a mamadeira, devido ao fluxo de leite facilitado. O uso da mamadeira também oferece maior flexibilidade para mães que trabalham fora, porém, pode fazer o bebê se acostumar ao bico da mamadeira. Em relação à chupeta, de certo modo, também favorece o desmame precoce, visto que, a mãe oferece a chupeta por não suportar o choro do bebê e, para acalmá-lo, pode negligenciar suas necessidades nutricionais (SANTOS CS, 2011).

A atividade contribuiu para a percepção da necessidade de promover mais ações de educação em saúde. Foi possível apontar mitos e crenças influenciam negativamente o sucesso do Aleitamento Materno Exclusivo e que é necessário que a cultura do conhecimento baseado em evidências se sobressaia em relação aos mitos que ainda permeiam o cotidiano da população envolvida. Tal conhecimento deve ser exposto de maneira simples, didática e com linguagem adequada ao público alvo para facilitar o entendimento. Apesar do número pequeno, cabe ressaltar que cada uma das participantes desta ação de educação em saúde se torna agente em potencial para a propagação de conhecimentos, demonstrando que a educação em saúde alcança lugares além do espaço onde é realizada. Levar informações de qualidade é fundamental para proporcionar melhorias na saúde e bem-estar destas mulheres, de seus filhos, familiares e amigos.

\section{REFERÊNCIAS}

1. ALBUQUERQUE RCCS, et al. Procedimento operacional padrão: aleitamento materno de primeira hora de vida da Maternidade Araken Irerê Pinto. Tese (Especialização em Enfermagem Obstétrica) - Rede Cegonha da Escola de Saúde da Universidade Federal do Rio Grande do Norte, Natal, Escola de Saúde da UFRN, 2019.

2. ALGARVES TR, et al. Aleitamento materno: Influência de mitos e crenças no desmame precoce. Rev. Saúde em foco, Teresina, 2015; 2(1): 151-167.

3. ARAGAKI IMM. Estudo sobre o traço e estado de ansiedade das nutrizes que apresentam indicadores de hipogalactia e nutrizes com hipogalactia normal/ Ilva Marico Mizumoto Aragali. Dissertação (Mestrado)-Escola de Enfermagem-Universidade de São Paulo, 122pg, 2002.

4. BASTABLE SB. O enfermeiro como educador: princípios de ensino-aprendizagem para a prática de enfermagem. $3^{\underline{a}}$ ed. Porto Alegre: Artemed, 2010.

5. BOER NCP. Fisiologia: curso prático. 1. ed. - Rio de Janeiro: Guamnabara Koogan, 2017.

6. BRASIL. 2014. Promovendo o aleitamento materno. Brasília: Ministério da Saúde. Secretaria de Atenção à Saúde. Disponível em: http://wwwunicef.org/brazil/pt/aleitamento.pdf. Acesso em: 09 set. 2020.

7. BRASIL. 2016. Ministério da Saúde. Dez passos para uma alimentação saudável: guia alimentar para crianças menores de dois anos. Brasília: Ministério da Saúde; Organização Pan-Americana de Saúde.

8. BRASIL. 2017. Mitos e verdades sobre aleitamento materno. Brasília: Ministério da Saúde. Disponível em: http://www.saude.gov.br/artigos/724-acoes-e-programas/banco-de-leite-humano/41044-mitos-e-verdades. Acesso em: 17 set. 2020. 
9. BRASIL. 2018. Saúde da criança: Nutrição Infantil: Aleitamento Materno e Alimentação Complementar. ed. 1. Brasília: Organização Mundial de Saúde. Secretaria de Atenção à Saúde. Departamento de Atenção Básica.

10. CAMPOS AMS. Práticas de aleitamento materno exclusivo informando pela mãe e oferta de líquidos aos seus filhos. Revista Latino-Am. Enfermagem, 2015; 23(2): 283-90.

11. COSTA FR. Resignificando o aleitamento materno: Ações educativas junto a uma comunidade de Brasília-DF. Tese (Especialização em Atenção Básica em Saúde da Família) - Universidade Federal do Mato Grosso do Sul, Campo Grande, 2015.

12. FALKENBERG MB, et al. Educação em saúde e educação na saúde: conceitos e implicações para a saúde coletiva. Ciência \& Saúde Coletiva, 2014; 19(3): 847-852.

13. FARIA MC. Fatores que favorecem ao desmame precoce no aleitamento materno. Tese (Especialização em Atenção Básica em Saúde da Família) - Universidade Federal de Minas Gerais, Pompeu, 2014.

14. LODI JC. Autoeficácia e fatores associados à manutenção do aleitamento materno exclusivo até o primeiro mês de vida da criança. Dissertação (Mestrado em Saúde Coletiva) - Universidade Estadual de Campinas, Piracicaba, 2016.

15. MARQUES ES, et al. Mitos e crenças sobre o aleitamento materno. Rev. Ciência \& Saúde Coletiva, Viçosa, 2011; 16(5): 2461-2468.

16. OLIVEIRA AKP, et al. Práticas e crenças populares associadas ao desmame precoce. Av Enfermagem, 207; 35(3): 303-312.

17. PEREIRA JR. Fatores relacionados ao desmame precoce: Um plano de ação. Tese (Especialização em Atenção Básica em Saúde da Família) - Universidade Federal de Minas Gerais, Lagoa Santa, 2014.

18. SANTOS CS. Aleitamento Materno: Principais Fatores Relacionados ao Desmame Precoce / Camila Silvério dos Santos. Fundação Educacional do Município de Assis /FEMA-Assis, 2011.

19. SANTOS EM, et al. Avaliação do aleitamento materno em crianças até dois anos assistidas na atenção básica do Recife, Pernambuco. Ciência \& Saúde Coletiva, 2019; 24(3): 1211-1222.

20. SEPKA GC, et al. Promoção do aleitamento materno com mães adolescentes: acompanhando e avaliando essa prática. Cogitare Enfermagem, 2007; 12(3): 313-22. 